\title{
Inhibition of Replicon Initiation in Human Cells Following Stabilization of Topoisomerase-DNA Cleavable Complexes
}

\author{
WILLIAM K. KAUFMANN, ${ }^{1,2,3,4 *}$ JAYNE C. BOYER,${ }^{2} \dagger$ LAUREL L. ESTABROOKS, ${ }^{3}$ \\ AND SANDRA J. WILSON ${ }^{1,4}$ \\ Department of Pathology, ${ }^{1}$ Curriculum in Toxicology, ${ }^{2}$ Curriculum in Genetics,${ }^{3}$ and Lineberger Comprehensive \\ Cancer Center, ${ }^{4}$ University of North Carolina at Chapel Hill, Chapel Hill, North Carolina 27599-7295
}

Received 26 September 1990/Accepted 15 April 1991

\begin{abstract}
Diploid human fibroblast strains were treated for $10 \mathrm{~min}$ with inhibitors of type I and type II DNA topoisomerases, and after removal of the inhibitors, the rate of initiation of DNA synthesis at replicon origins was determined. By alkaline elution chromatography, $4^{\prime}$-(9-acridinylamino)methanesulfon-m-anisidide (amsacrine), an inhibitor of DNA topoisomerase II, was shown to produce DNA strand breaks. These strand breaks are thought to reflect drug-induced stabilization of topoisomerase-DNA cleavable complexes. Removal of the drug led to a rapid resealing of the strand breaks by dissociation of the complexes. Velocity sedimentation analysis was used to quantify the effects of amsacrine treatment on DNA replication. It was demonstrated that transient exposure to low concentrations of amsacrine inhibited replicon initiation but did not substantially affect DNA chain elongation within operating replicons. Maximal inhibition of replicon initiation occurred 20 to $30 \mathrm{~min}$ after drug treatment, and the initiation rate recovered 30 to 90 min later. Ataxia telangiectasia cells displayed normal levels of amsacrine-induced DNA strand breaks during stabilization of cleavable complexes but failed to downregulate replicon initiation after exposure to the topoisomerase inhibitor. Thus, inhibition of replicon initiation in response to DNA damage appears to be an active process which requires a gene product which is defective or missing in ataxia telangiectasia cells. In normal human fibroblasts, the inhibition of DNA topoisomerase I by camptothecin produced reversible DNA strand breaks. Transient exposure to this drug also inhibited replicon initiation. These results suggest that the cellular response pathway which downregulates replicon initiation following genotoxic damage may respond to perturbations of chromatin structure which accompany stabilization of topoisomerase-DNA cleavable complexes.
\end{abstract}

DNA topoisomerases are a class of nuclear enzymes which are capable of forming covalent complexes with DNA. Formation of these complexes involves scission of the phosphodiester backbone of DNA, with covalent linkage of the topoisomerase to one end of the cutting site $(6,13,40)$. The other cut end apparently remains associated with the topoisomerase. These complexes of topoisomerase associated with cut or cleaved DNA are known as cleavable complexes. For type I topoisomerases from mammalian cells, a single DNA break is produced in the complex, and free rotation of the cut strand about the intact strand allows relaxation of supercoiled molecules. Type II topoisomerases produce closely opposed cuts in the two strands of duplex DNA, allowing passage of strands through the DNA duplex.

The formation of topoisomerase-DNA complexes which allow relaxation of supercoiled DNA or passage of double strands of DNA may facilitate transcription of RNA and replication of DNA $(3,5,9)$. Both type I and type II topoisomerases have been shown to play roles in replication of the simian virus 40 (SV40) circular replicon in a cell-free system $(37,42)$. Topoisomerase I was found to contribute to chain elongation, presumably by relieving supercoiling tension in front of advancing replication forks. This function could be replaced by topoisomerase II. Topoisomerase II was also required for the final stages of separation of the topologically intertwined sister duplexes. This result was consistent with demonstrations that temperature-sensitive

\footnotetext{
* Corresponding author.

$\dagger$ Present address: Laboratory of Molecular Genetics, National Institute of Environmental Health Sciences, Research Triangle Park, NC 27709.
}

topoisomerase II yeast mutants were arrested in $\mathrm{G}_{2}$ when incubated at the restrictive temperature (7). Recent results also implicate topoisomerases as endogenous suppressors of homologous recombination (41). The vital nature of these enzyme activities is exemplified by the demonstration that they are the targets for a variety of cytotoxic drugs used clinically to treat certain cancers $(34,39)$. Many of these drugs stabilize the topoisomerase-DNA cleavable complex, and the resulting DNA strand breaks can be discerned with a strong protein denaturant. Topoisomerase inhibitors produce dramatic cytogenetic damage, including sister chromatid exchange and chromosome aberrations (17). Thus, the mechanism of drug action is of interest for the rational design of drug therapy regimens.

To date, there have been few studies of the mechanisms of inhibition of DNA replication by drugs which interfere with topoisomerase activity. Flow cytometric analysis had revealed a delayed progression of human leukemic cells through $S$ phase during incubation with etoposide [ $4^{\prime}$-demethylepipodophyllotoxin-9-(4,6-O-ethylidene- $\beta$-D-glucopyranoside)], an inhibitor of type II topoisomerase (16). Inhibition of DNA synthesis was postulated to be the result of an effect on replicon initiation. Inhibition of DNA and RNA synthesis has also been observed in cells treated with camptothecin, an inhibitor of type I topoisomerase (12).

In this study, we have used alkaline elution chromatography to quantify the numbers of topoisomerase-DNA complexes that are formed during exposure of human cells to inhibitors of type I and type II topoisomerases. Velocity sedimentation analysis was used to quantify drug-induced effects on replicon initiation and DNA chain elongation. The results suggest that the biological damage to DNA induced 
by stabilizing topoisomerase-DNA complexes triggers a stereotypic adaptive response pathway that produces a rapid downregulation of the replicon initiation rate. Disregulation of this pathway may have profound pathologic consequences, as exemplified by the enhanced frequencies of DNA metabolic errors in ataxia telangiectasia (AT) cells (1, $8,23,35)$.

\section{MATERIALS AND METHODS}

Human cell strains and cell culture conditions. Diploid human fibroblasts were derived from foreskin in this laboratory (NHF-1) or obtained from the Human Genetic Mutant Cell Respository (a normal strain, GM3348, and an AT strain, AT4BE [GM3487B]) and the American Type Culture Collection (xeroderma pigmentosum [XP] strain XP4BE [CRL1162]). An SV40-transformed XP line (GM4429B) and a large-T-antigen transformed AT line (GM9607) were obtained from the Human Genetic Mutant Cell Repository. The SV80 fibroblast line (SV40 transformed) was provided by Betsy Sutherland, Brookhaven National Laboratory. Normal and AT lymphoblastoid cell lines were provided by Michael Swift, University of North Carolina at Chapel Hill. Diploid and transformed fibroblasts were grown as described previously (19). Lymphoblasts were grown in RPMI 1640 medium supplemented with $2 \mathrm{mM}$ L-glutamine, $20 \%$ fetal bovine serum, $200 \mu \mathrm{g}$ of kanamycin per $\mathrm{ml}$, and $50 \mu \mathrm{g}$ of gentamicin per $\mathrm{ml}$. Prior to drug treatment and analysis of strand breakage or DNA replication, cells were grown for at least two generations in medium containing $\left[{ }^{14} \mathrm{C}\right]$ thymidine $(50 \mathrm{Ci} / \mathrm{mol} ; 5$ to $20 \mathrm{nCi} / \mathrm{ml})$. Cells were then incubated in isotope-free medium for at least $4 \mathrm{~h}$ before experimental treatments.

Drug treatment. Camptothecin and amsacrine were supplied by the Natural Products Branch, Division of Cancer Treatment, National Cancer Institute. For cells growing on plastic dishes, drugs were added in dimethyl sulfoxide (final concentration of solvent was $0.5 \%$ ). After $10 \mathrm{~min}$ of incubation at $37^{\circ} \mathrm{C}$, the medium was removed, the cells were rinsed twice with warm Hanks balanced salt solution, and fresh growth medium was added. For suspension cultures of lymphoblasts, cells were sedimented out of drug-containing medium and then resuspended in fresh drug-free medium.

Alkaline elution chromatography. For determination of DNA breakage by alkaline elution, monolayer cell cultures were harvested by scraping into ice-cold phosphate-buffered saline. Suspension cultures were sedimented and resuspended in the same buffer. Cells were deposited on polycarbonate filters, lysed, and washed with alkaline elution buffer as described previously (21). We found that addition of proteinase $\mathrm{K}$ to the lysis solution had no effect on DNA elution from the polycarbonate filters, and therefore proteinase treatment during lysis was not included. The initial rate of elution of DNA during washing with alkaline buffer was quantified from the release of ${ }^{14} \mathrm{C}$ radioactivity from filters and converted to a frequency of DNA strand breaks according to a calibration curve (21).

Velocity sedimentation analysis. Analysis of DNA replication in drug-treated cells was done as previously described $(4,19)$. Briefly, following drug treatment, $\left[{ }^{14} \mathrm{C}\right]$ thymidinelabeled cells were incubated for 10 or 15 min with $\left[{ }^{3} \mathrm{H}\right]$ thymidine $(10$ to $50 \mu \mathrm{Ci} / \mathrm{ml} ; 56 \mathrm{Ci} / \mathrm{mmol})$. Cells were harvested by scraping or by sedimentation and lysed on top of 5 to $20 \%$ alkaline sucrose gradients. After sedimentation at 25,000 rpm for $4 \mathrm{~h}$, the gradients were fractionated, and acidinsoluble radioactivity was quantified. Within an experiment

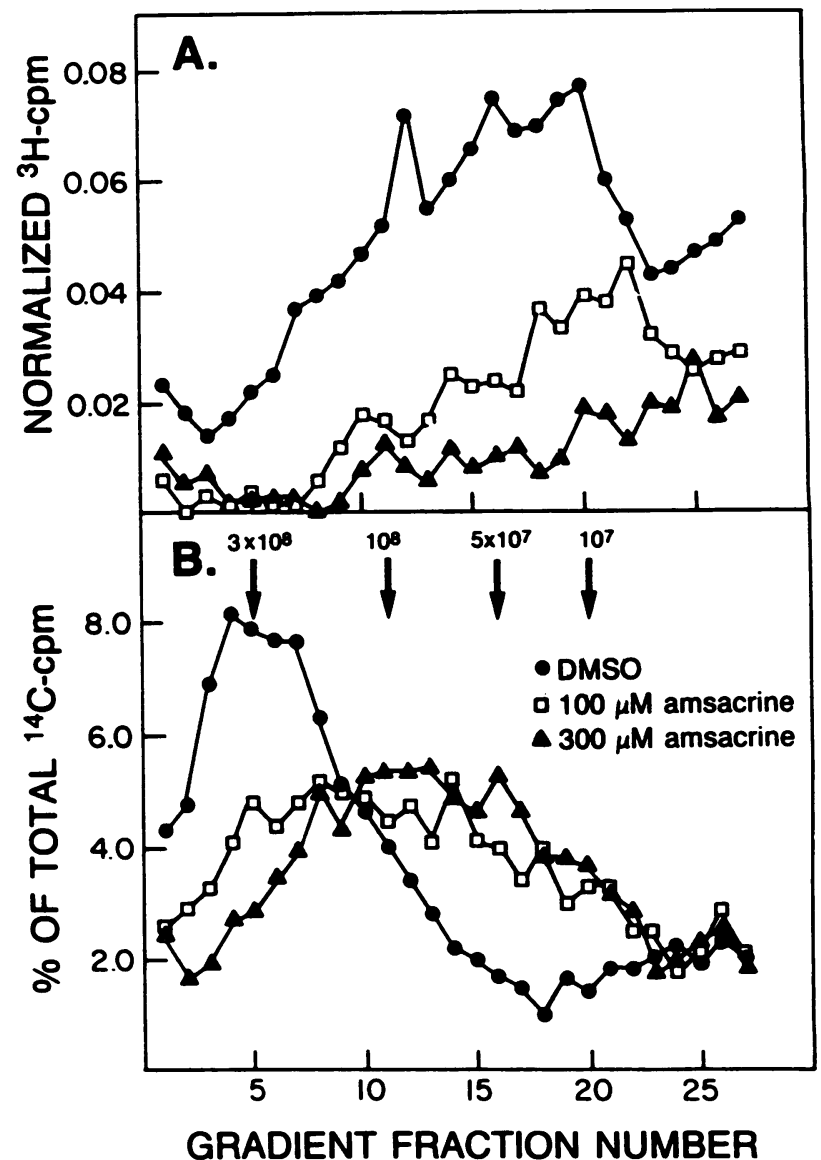

FIG. 1. Inhibition of DNA synthesis and fragmentation of parental DNA in amsacrine-treated fibroblasts. XP variant fibroblasts (XP4BE) were treated with 100 or $300 \mu \mathrm{M}$ amsacrine for $30 \mathrm{~min}$ and then pulsed with $\left[{ }^{3} \mathrm{H}\right]$ thymidine for $10 \mathrm{~min}$ in drug-free medium. Cells were harvested, and DNA strand sizes were evaluated by velocity sedimentation in alkaline sucrose gradients. (A) Normalized ${ }^{3} \mathrm{H}$ cpm represent the acid-insoluble ${ }^{3} \mathrm{H}$ radioactivity in each gradient fraction divided by the total acid-insoluble ${ }^{14} \mathrm{C}$ radioactivity in the gradient. Profiles therefore depict the rates of synthesis of DNA in various size classes of nascent intermediates normalized to constant cell number. Total ${ }^{3} \mathrm{H} \mathrm{cpm}$ in these gradients were 2,422 , 864 , and 424 for solvent-treated controls (solid circles), $100 \mu \mathrm{M}$ amsacrine-treated cells (open squares), and $300 \mu \mathrm{M}$ amsacrinetreated cells (solid triangles), respectively. (B) Profiles of $\left[{ }^{14} \mathrm{C}\right]$ thymidine-labeled parental DNA. Total ${ }^{14} \mathrm{C} \mathrm{cpm}$ were 1,300 to 1,800 $\mathrm{cpm}$. Symbols are as in panel A. Sedimentation was from right to left. Approximate DNA molecular weights are indicated by vertical arrows. DMSO, dimethyl sulfoxide.

with replicate cell cultures, the level of incorporation of $\left[{ }^{14} \mathrm{C}\right]$ thymidine was used as an estimate of cell numbers. The $\left[{ }^{3} \mathrm{H}\right]$ Thymidine that was incorporated during a 10 - to $15-\mathrm{min}$ pulse was normalized to the cell number. The steady-state distribution of nascent DNA molecules, which was revealed by the profile of ${ }^{3} \mathrm{H}$ radioactivity (19), was therefore also a representation of DNA synthesis activity in replicons at various levels of maturation (31). In practice, we looked for drug-induced changes in the incorporation of $\left[{ }^{3} \mathrm{H}\right]$ thymidine into replication intermediates that had initiated synthesis before the drug treatment (which reveals rates of chain elongation in operating replicons) and into replicons that initiated synthesis after the drug treatment (which reveals 


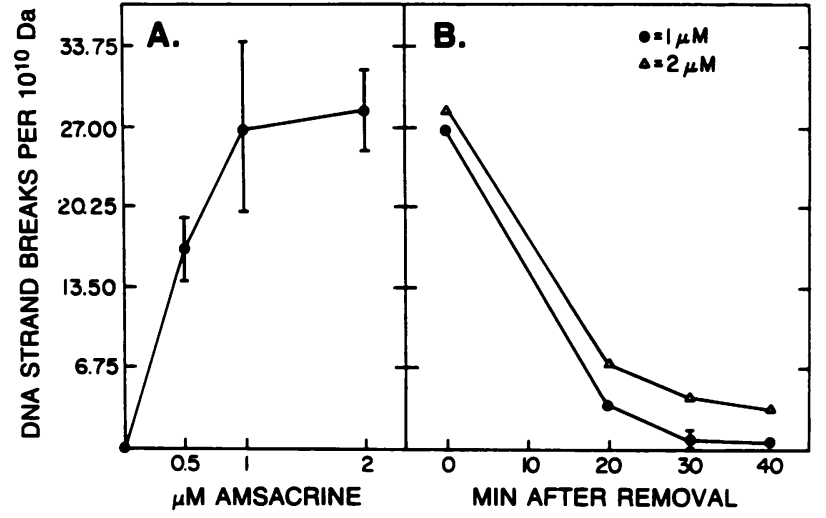

FIG. 2. DNA strand breaks in amsacrine-treated human fibroblasts. Confluent cultures of NHF-1 cells were treated with various concentrations of amsacrine for $10 \mathrm{~min}$ and either harvested immediately for alkaline elution analysis (A) or incubated in drug-free medium for various intervals after removal of amsacrine (B). The low background number of strand breaks in solvent-treated controls $\left(<2\right.$ per $10^{10} \mathrm{Da}$ ) has been subtracted. Error bars depict 1 standard deviation about the mean $(n=3)$.

rates of replicon initiation). Calibration of the gradients with size standards had been done previously (19).

Cell synchronization. Diploid human fibroblasts were arrested in $\mathrm{G}_{0}$ by growth to confluence followed by 3 days of incubation in medium containing $0.5 \%$ serum. Proliferating cells were synchronized to $G_{1}$ by first arresting them at confluence and then replating at lower cell density into fresh medium. After $7 \mathrm{~h}$, the cells were in $G_{1}$. Addition of aphidicolin at $6 \mu \mathrm{M}$ after arrested cells were replated caused up to $80 \%$ of the cells to accumulate at the beginning of the $\mathrm{S}$ phase (21). Removal of the aphidicolin after $24 \mathrm{~h}$ released these cells into the $S$ phase. Cells were sampled $3 \mathrm{~h}$ after removal of aphidicolin, when in the middle of $S$, or $7 \mathrm{~h}$ after removal of aphidicolin, when in $G_{2}$. Cells collected in the various cell cycle phases $\left(G_{0}, G_{1}, S\right.$, and $\left.G_{2}\right)$ were incubated with $2 \mu \mathrm{M}$ amsacrine for $10 \mathrm{~min}$ before determination of DNA strand breaks by alkaline elution.

\section{RESULTS}

A pilot experiment was done first with high concentrations of amsacrine. XP variant fibroblasts (4) were incubated for 30 min with 100 or $300 \mu \mathrm{M}$ amsacrine, and immediately after removal of the drug, rates of DNA synthesis were quantified after a 10 -min pulse with $\left[{ }^{3} \mathrm{H}\right]$ thymidine. Cells were lysed on top of alkaline sucrose gradients, and nascent $\left({ }^{3} \mathrm{H}\right.$-labeled) and parental $\left({ }^{14} \mathrm{C}\right.$-labeled) DNA strands were separated according to size by velocity sedimentation. $\left[{ }^{3} \mathrm{H}\right]$ Thymidine incorporation into acid-insoluble DNA was normalized to cell number, which allows quantification of the synthesis of nascent DNA molecules at various stages of processing (19, 31). Drug treatment severely inhibited DNA replication, as reflected in the reduced incorporation of precursor into all size classes of nascent DNA (Fig. 1A). These concentrations of drug also produced breaks in parental DNA (Fig. 1B).

Subsequent studies were done in which cells were incubated with lower concentrations of amsacrine for $10 \mathrm{~min}$ and DNA fragmentation was quantified by alkaline elution. This technique relies upon the fact that DNA strand breaks facilitate the unwinding of DNA in alkali and increase the initial rate of release of DNA from polycarbonate filters.

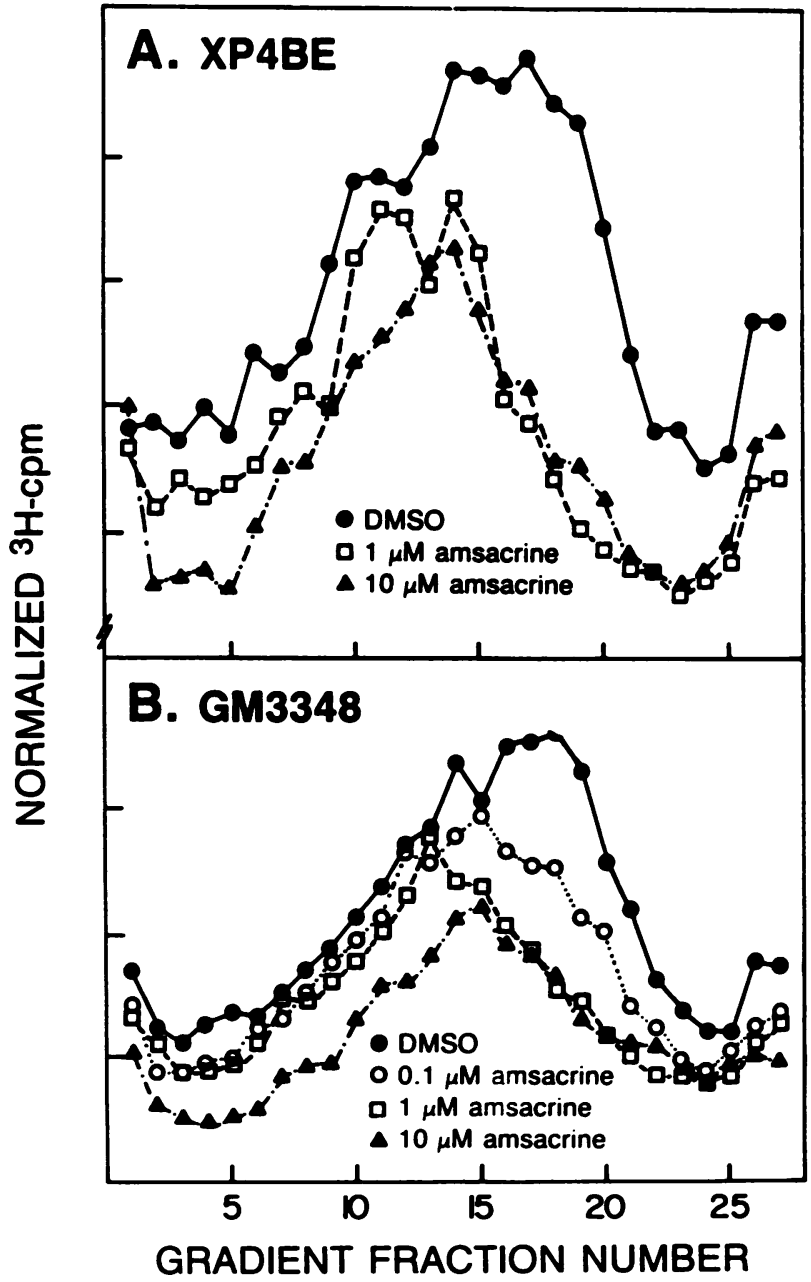

FIG. 3. Concentration-dependent inhibition of DNA replication by amsacrine. Diploid fibroblast strains, both XP variants $(A)$ and normals (B), were treated with various concentrations of amsacrine for $10 \mathrm{~min}$ and then incubated in drug-free medium for $\mathbf{3 0 ~ m i n}$. Cells were incubated with $\left[{ }^{3} \mathrm{H}\right]$ thymidine for $15 \mathrm{~min}$ and then harvested for velocity sedimentation analysis. (A) XP variant fibroblasts: circles, solvent (DMSO)-treated control; squares, $1.0 \mu \mathrm{M}$ amsacrine; triangles, $10 \mu \mathrm{M}$ amsacrine. Total ${ }^{14} \mathrm{C}, 1,600$ to $2,900 \mathrm{cpm}$; total ${ }^{3} \mathrm{H}, 4,300$ to $5,000 \mathrm{cpm}$. (B) Normal human fibroblasts. Solid circles, solvent (DMSO)-treated control; open circles, $0.1 \mu \mathrm{M}$ amsacrine; squares, $1.0 \mu \mathrm{M}$ amsacrine; triangles, $10 \mu \mathrm{M}$ amsacrine. Total ${ }^{14} \mathrm{C}, 570$ to $620 \mathrm{cpm}$; total ${ }^{3} \mathrm{H}, 5,000$ to $9,000 \mathrm{cpm}$. The increments of normalized ${ }^{3} \mathrm{H} \mathrm{cpm}$ are 0.025 and $0.25 \mathrm{cpm}$, respectively, in panels A and B.

These filters do not bind protein well, especially after cells are lysed in sodium dodecyl sulfate $(22,25)$, and treatment of cell lysates with proteinase $\mathrm{K}$ before adding alkali had no effect on DNA elution (results not shown). Concentrations of amsacrine in the range of 0.05 to $1 \mu \mathrm{M}$ produced a dose-dependent increase in the frequency of DNA strand breaks (Fig. 2A). A plateau in the response was seen after a higher concentration, suggesting saturation. The maximal frequency of DNA strand breaks was 3 breaks per $10^{9} \mathrm{Da}$. When medium containing amsacrine was removed from cell cultures, reversal of strand breakage occurred (Fig. 2B). By $30 \mathrm{~min}$ after removal of $1 \mu \mathrm{M}$ amsacrine, the frequency of DNA strand breaks was equivalent to those seen in un- 


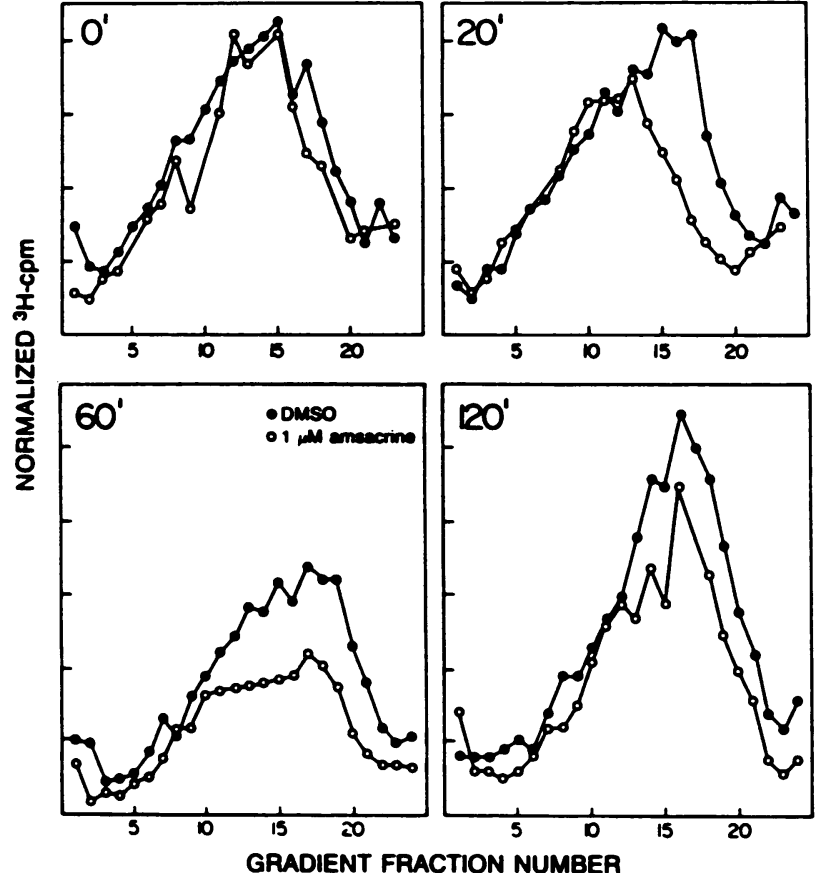

FIG. 4. Inhibition of replicon initiation by amsacrine. Diploid fibroblasts (NHF-1) were treated with DMSO or $1 \mu \mathrm{M}$ amsacrine for $10 \mathrm{~min}$ and then washed free of drug. Cells were incubated with $\left[{ }^{3} \mathrm{H}\right]$ thymidine for $15 \mathrm{~min}$, beginning immediately or 20,60 , or 120 min after addition of drug-free medium. Total ${ }^{14} \mathrm{C}, 1,800$ to 2,000 $\mathrm{cpm}$; total ${ }^{3} \mathrm{H}, 2,500$ to $6,000 \mathrm{cpm}$. Increments of normalized ${ }^{3} \mathrm{H} \mathrm{cpm}$ are $0.05 \mathrm{cpm}$.

treated controls. For the purposes of this presentation, it will be assumed that the DNA strand breaks induced by topoisomerase inhibitors reflect the presence of stabilized topoisomerase-DNA cleavable complexes.

To examine the effect on DNA replication of brief inhibition of topoisomerase II activity, we first examined two strains of human fibroblasts which had previously been distinguished in the laboratory (4) by their capacity for postreplication repair after exposure to carcinogens. XP variant and normal diploid human fibroblast strains were treated with various concentrations of amsacrine and then incubated for $30 \mathrm{~min}$ in drug-free medium before DNA replication was assayed by velocity sedimentation. Exposing the normal fibroblast strain GM3348 to $0.1 \mu \mathrm{M}$ amsacrine modestly inhibited incorporation of precursor into molecules of about $20 \mathrm{MDa}$ and smaller (fractions 17 to 20) without noticeably affecting DNA synthesis in larger intermediates (Fig. 3B). The average replicon size in diploid human fibroblasts is $20 \mu \mathrm{m}$, and a single-stranded DNA molecule of 20 $\mathrm{MDa}$ has a mass one-half that of an average replicon. After exposure to $1 \mu \mathrm{M}$ amsacrine, DNA synthesis in such halfreplicon-size intermediates $(20 \mathrm{MDa})$ was inhibited by about $50 \%$, while synthesis in multireplicon-size intermediates (fractions 5 to 13) remained near control rates. This selective inhibition of DNA synthesis in half-replicon-size intermediates is characteristic of inhibition of replicon initiation (19, 20, 29-32). A higher concentration of drug $(10 \mu \mathrm{M})$ reduced synthesis in multireplicon-size intermediates by about 30 to $70 \%$, suggesting that residual levels of the drug also inhibited chain elongation within operating replicons $(19,20)$. An identical pattern of inhibition of DNA replication was seen in

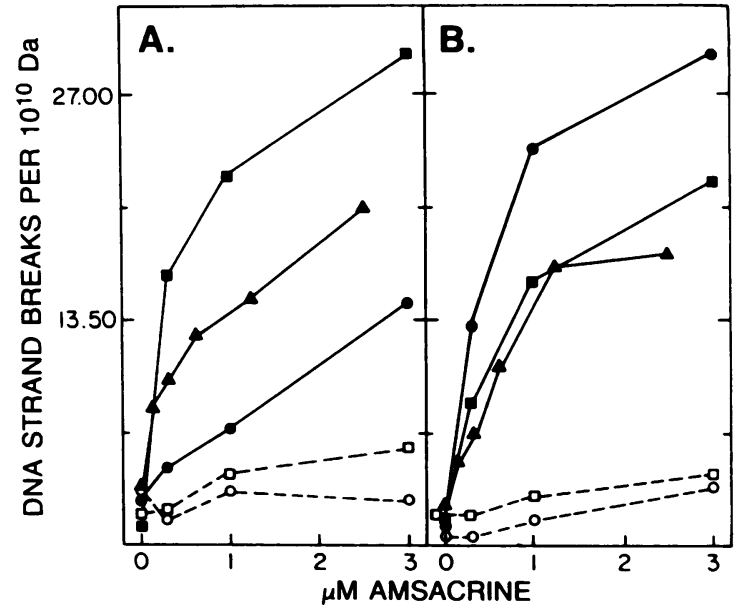

FIG. 5. Amsacrine-induced DNA strand breaks in AT cells. Human cell strains or lines were treated with various concentrations of amsacrine for $10 \mathrm{~min}$ and harvested immediately (solid symbols) or after 30 min of incubation in drug-free medium (open symbols). (A) Circles, AT4BE, diploid AT fibroblasts; squares, GM9607, T-antigen-transformed AT fibroblasts; triangles, 590 AT, lymphoblastoid AT cells. (B) Circles, SV80, SV40-transformed normal human fibroblasts; squares, GM4429B, SV40-transformed XP fibroblasts; triangles, $599 \mathrm{~N}$, normal lymphoblastoid cells.

the XP variant fibroblast strain (Fig. 3A), which had previously been shown to be defective in a pathway of postreplication repair after UV irradiation (4). The XP variant cells did not appear to be hypersensitive to treatment with the topoisomerase inhibitor.

To determine the generality of the response in normal human fibroblasts and to further characterize its features, time course studies were done with another diploid strain, NHF-1, that had been treated with the low concentration (1 $\mu \mathrm{M})$ of amsacrine (Fig. 4). Immediately after removal of the drug, there was little change in sedimentation profiles, although the reduction in radioactivity in fractions 17 to 20 is consistent with early phases of inhibition of replicon initiation. By 20 min after removal of drug, the effect on replicon initiation was more fully exposed. The point at which the profile for treated cells diverged from that for the control had moved from fraction 17 at time zero $(10 \mathrm{~min}$ of drug exposure) to fraction 14 by $20 \mathrm{~min}$ after removal of the drug. By 60 min after removal of the drug, the point of divergence had moved to fraction 11. At this time, DNA synthesis in half-replicon-size intermediates (fractions 17 to 20) had begun to recover, and by $2 \mathrm{~h}$ after removal of the amsacrine, rates of initiation of DNA synthesis had recovered to near control levels. This pattern of inhibition of DNA synthesis sweeping with time from low-molecular-weight intermediates to higher-molecular-weight nascent molecules is identical to the pattern of cellular response to DNA damage produced by low doses of UV light, ionizing radiation, and benzo $[a]$ pyrene diolepoxide I $(19,20,31)$. Experiments similar to these done with etoposide, a nonintercalative inhibitor of type II topoisomerase, revealed the same pattern of response (18).

AT cells display radioresistant DNA synthesis, in which the pathway for downregulation of replicon initiation appears to be defective $(30,32)$. It had been reported that AT cells may express reduced levels of topoisomerase II (26). To test for a possible deficit in topoisomerase II activity in 


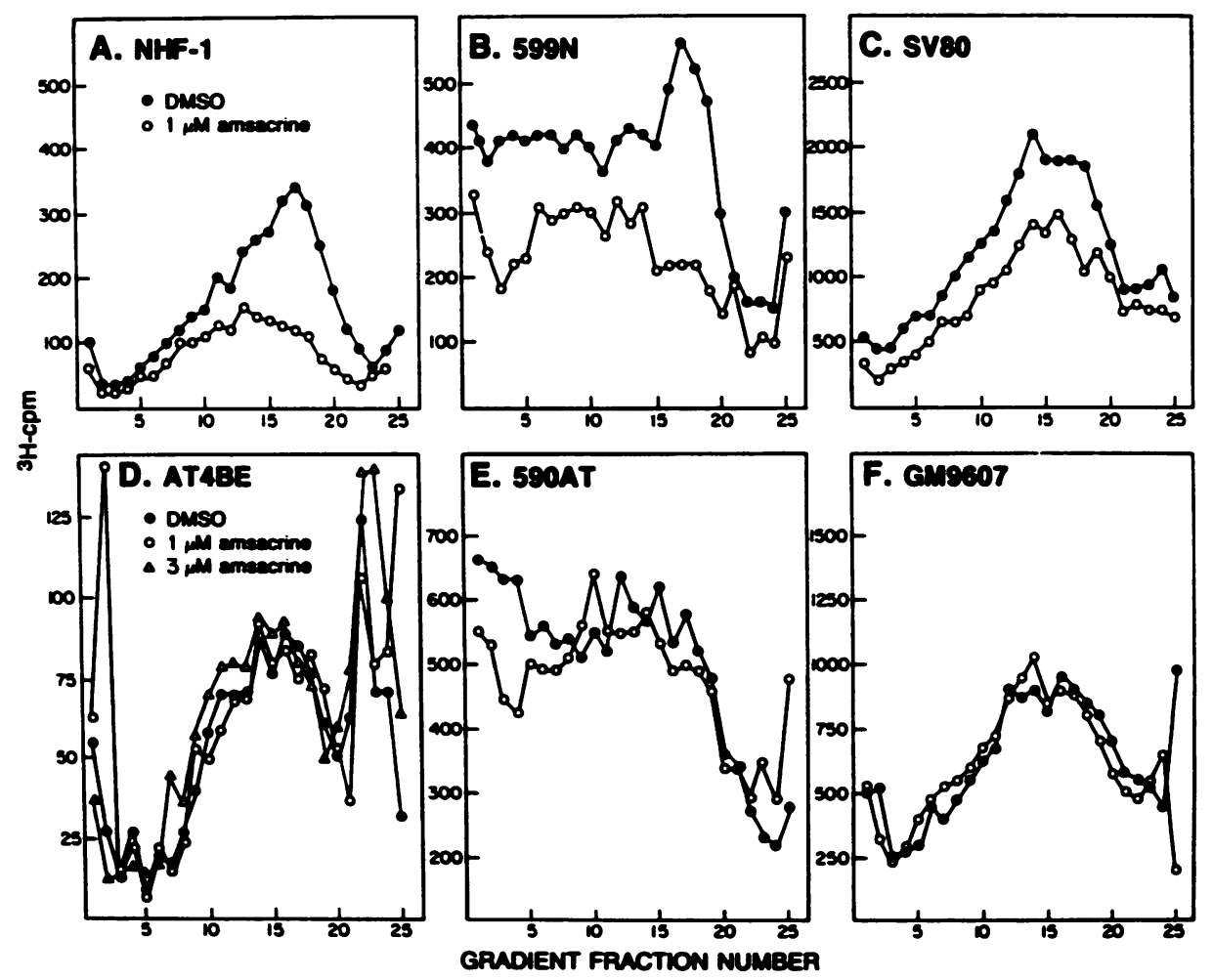

FIG. 6. Amsacrine resistant replicon initiation in AT cells. The cell strains or lines described in the legend to Fig. 5 were treated with 1 $\mu \mathrm{M}$ amsacrine (open circles), $3 \mu \mathrm{M}$ amsacrine (open triangles, panel D) or DMSO (solid circles) for $10 \mathrm{~min}$, and after $30 \mathrm{~min}$ of incubation in fresh drug-free medium, the cells were pulsed for $15 \mathrm{~min}$ with $\left[{ }^{3} \mathrm{H}\right]$ thymidine. Rates of DNA synthesis in various size classes of replication intermediates were determined by velocity sedimentation analysis. (A) NHF-1; (B) 599N; (C) SV80; (D) AT4BE; (E) 590AT; (F) GM9607. The net ${ }^{3} \mathrm{H} \mathrm{cpm}$ in gradient fractions are depicted, as the total ${ }^{14} \mathrm{C} \mathrm{cpm}$ in paired gradients were equal.

AT cells, various AT cells were treated with amsacrine, and then DNA strand breakage and replicon initiation were quantified. In each of the AT cell cultures, exposure to amsacrine produced DNA strand breaks which were reversed upon removal of drug (Fig. 5A). This transient exposure to amsacrine had, however, no effect on DNA replication in the diploid, lymphoblast, and large-T-antigentransformed AT cells (Fig. 6D, E, and F). Amsacrine was also shown to produce reversible DNA strand breaks in SV40-transformed normal and XP fibroblast lines and a normal lymphoblastoid line (Fig. 5B). The normal lymphoblastoid line and the SV40-transformed normal fibroblast line responded to the amsacrine as did the normal diploid fibroblasts, with inhibition of replicon initiation (Figure 6A, B, and $\mathrm{C}$ ). The inhibition of chain elongation in active replicons seen in some of the amsacrine-treated cells (Fig. 6B and C) probably reflects the presence of residual drug.

The diploid AT strain appeared to express fewer topoisomerase-associated strand breaks than the transformed AT cells and the normal diploid fibroblast strain (Fig. 2 and 5A). This was considered to reflect a lower growth fraction in the diploid AT strain, with topoisomerase II levels being related to cell proliferation activity. To test for cell proliferationdependent regulation of topoisomerase II, the diploid foreskin fibroblast strain NHF-1 was arrested in $G_{0}$ or synchronized to the $G_{1}, S$, or $G_{2}$ phase of the cell cycle (21), and levels of amsacrine-induced DNA strand breaks were quantified by alkaline elution. $G_{0}$ and $G_{1}$ cells expressed about $60 \%$ as many DNA strand breaks as $S$ and $G_{2}$ cells (results not shown). All analyses of topoisomerase-dependent DNA strand breakage in diploid cells (Fig. 2, 5, and 7) were done with cells arrested in $G_{0}$ by growth to confluence followed by 3 days of incubation in $0.5 \%$ serum. Consequently, the levels of stabilized topoisomerase-DNA complexes in diploid cells presented in Fig. 2 and 5 probably underestimate the number of these complexes in $\mathrm{S}$-phase cells by about one-half.

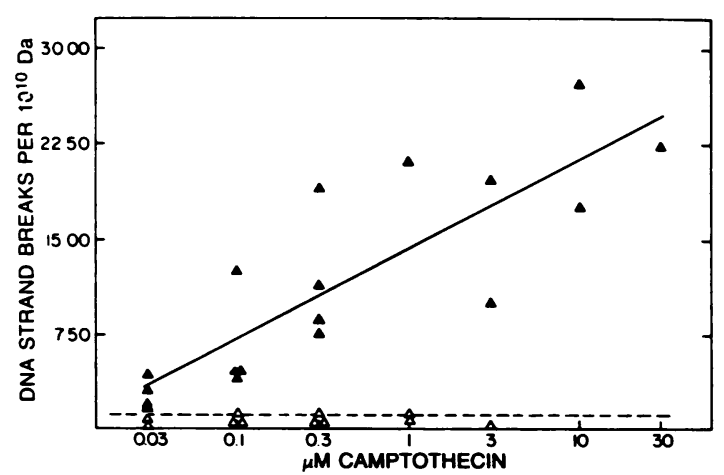

FIG. 7. Camptothecin-induced DNA strand breaks. The NHF-1 fibroblast strain was incubated with various concentrations of camptothecin for $10 \mathrm{~min}$ and either harvested immediately (solid symbols) or incubated for an additional $30 \mathrm{~min}$ in drug-free medium (open symbols). DNA strand breaks were determined by alkaline elution analysis. The dashed line depicts the average number of strand breaks seen in solvent-treated controls. The solid line was calculated by linear regression of the logarithm of camptothecin concentration against DNA strand breaks. 


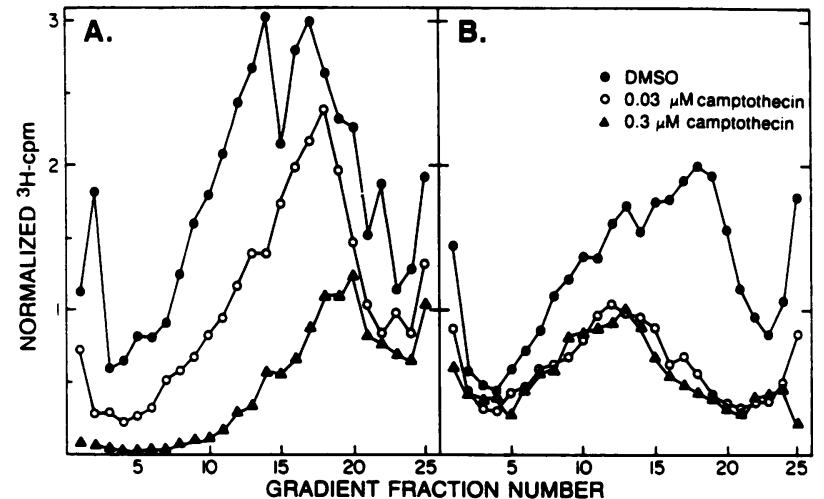

FIG. 8. Inhibition of DNA replication by camptothecin. (A) NHF-1 fibroblasts were incubated with camptothecin for $25 \mathrm{~min}$ and with $\left[{ }^{3} \mathrm{H}\right]$ thymidine for the last $15 \mathrm{~min}$ of drug exposure. (B) Replicate cultures were treated with camptothecin for $10 \mathrm{~min}$ and then incubated in drug-free medium for $30 \mathrm{~min}$ before being pulsed with $\left[{ }^{3} \mathrm{H}\right]$ thymidine for $15 \mathrm{~min}$. Rates of DNA synthesis in various size classes of replication intermediates were determined by velocity sedimentation analysis. Solid circles, solvent-treated control; open circles, $0.03 \mu \mathrm{M}$ camptothecin; solid triangles, $0.3 \mu \mathrm{M}$ camptothecin. Total ${ }^{14} \mathrm{C}$ was $3,000 \mathrm{cpm}$ in this experiment.

Analyses of DNA strand breaks in amsacrine-treated transformed cells were done with cells in log-phase growth, in which all cell cycle phases are represented.

Given the stereotypic pattern of response to inhibition of topoisomerase II, an inhibitor of topoisomerase I was studied to see whether the response pathway recognized the stabilization of a different cleavable complex. Camptothecin was shown to produce DNA strand breaks which were fully reversed within 30 min after removal of the drug (Fig. 7). During continuous exposure to camptothecin, DNA replication was inhibited in multireplicon-size intermediates, suggesting that the cleavable complexes interfere with DNA chain elongation (Fig. 8A). However, when the drug was removed, this inhibition was reversed and the inhibition of replicon initiation became evident. Some residual effect on DNA synthesis in multireplicon-size intermediates was seen after removal of camptothecin, but this was not concentration dependent. Indeed, very low levels of drug-induced damage to DNA appeared to be sufficient to inhibit replicon initiation. A maximal effect was seen after exposure to 0.03 $\mu \mathrm{M}$ camptothecin, which induced only about 3 DNA breaks per $10^{10} \mathrm{Da}$.

\section{DISCUSSION}

Transient freezing of topoisomerase-DNA cleavable complexes was demonstrated to activate a stereotypic response pathway involving selective downregulation of the rate of replicon initiation. This response was seen following exposure to inhibitors of topoisomerase II (amsacrine and etoposide [18]) and topoisomerase I (camptothecin) in normal human fibroblasts. This response pathway was also demonstrated in normal human lymphoblasts, transformed fibroblasts, and diploid XP variant fibroblasts after inhibition of topoisomerase II with amsacrine. The inhibition of replicon initiation was not seen in two AT cell lines or a diploid AT strain after treatment with amsacrine. This implies that the radioresistant DNA synthesis which characterizes the AT phenotype is expressed at the level of a generalized adaptive response pathway triggered by perturbation of chromatin
DNA structure. AT cells are also defective in downregulation of replicon initiation after $U V$ and ionizing radiation treatment $(30,32)$. In comparison to normal cells and AT heterozygotes, AT homozygotes may express approximately 10-fold-higher frequencies of radiation-induced chromatidtype chromosomal aberrations (8). AT cells were reported to be hypersensitive to killing by etoposide $(11,36)$, consistent with a model that inhibition of replicon initiation protects against genotoxic damage (29).

The mechanisms of action of the topoisomerases have been extensively investigated, as have the effects of the topoisomerase inhibitors $(6,13,40)$. Amsacrine intercalates into the DNA duplex, whereas etoposide has weak DNAbinding activity. Both drugs stabilize the topoisomerase II-DNA cleavable complex. The levels of drug-induced DNA strand breaks identified in these studies are quite similar to those identified previously in diploid human fibroblast strains $(44,45)$, and the AT cells were confirmed to express normal levels of amsacrine-dependent DNA breakage (45). Levels of amsacrine-dependent DNA strand breaks were moderately affected by proliferative status in the foreskin fibroblast strain, with quiescent $G_{0}$ cells exhibiting $60 \%$ as many strand breaks as $S$-phase and $\mathbf{G}_{2}$-phase proliferating cells. This modest variation in amsacrine-dependent strand breaks between quiescent and proliferating cells is in good agreement with results reported by Zwelling et al. (44), who used very similar assay conditions. The observation that the cellular levels of topoisomerase II, as determined by immunoblotting, may vary in diploid human fibroblast strains by as much as 20 -fold between quiescence and active growth (15) suggests that the amsacrine-induced DNA strand breaks which are seen by alkaline elution analysis reflect the activity of only a small fraction of the cellular topoisomerase II.

Although topoisomerases appear to provide a swivel action to relieve topological strain or supercoiling tension and to separate intertwined daughter chromatids, stabilization of the topoisomerase II-DNA cleavable complex with amsacrine does not appear to allow relaxation of nucleoid structures (33). Consequently, even though the phosphodiester bond is cut and only one cut end of DNA is covalently linked to protein, the other cut end appears to be held by the protein in a way which retains or preserves chromatin topological structure. In spite of this apparent lack of alteration in chromatin supercoiling tension during stabilization of the cleavable complex, human cells recognize some alteration associated with a brief exposure to the inhibitor and activate the pathway of downregulation of the replicon initiation rate. It appears at first glance to be paradoxical that the rate of replicon initiation would be reduced by inhibiting the separation of intertwined daughter chromatids with the topoisomerase II inhibitors. We had previously suggested that by stabilizing the topoisomerase-DNA complex, the replication complex would remain occupied and would not be available for initiating replication within replicon clusters (18). This direct steric effect does not appear to be the case because, according to such a model, the AT cells should display inhibition of replicon initiation, which they do not. Intercalation also does not appear to be necessary to trigger the response, because the nonintercalative inhibitor etoposide is active (18). Consequently, we now suggest that critical DNA damage is produced when DNA replication occurs in the vicinity of topoisomerase-DNA complexes, and it is this damage which activates downregulation of replicon initiation. AT cells are unable to activate this response pathway owing to their underlying genetic defect. It has been proposed that progression of DNA replication 
forks into cleavable complexes may produce lethal cellular damage (14). Denaturation of duplex strands at the sites of cleavable complexes could produce irreversible DNA double-strand breaks, which lead to lethal chromatid aberrations $(2,18)$. Because topoisomerases appear to be required for replication and may be integral components of the replication complex (27), such a mechanism of drug-induced genetic damage would be very efficient. The observation that essentially continuous exposure to camptothecin and amsacrine inhibited DNA chain elongation in operating replicons is consistent with a model that drug-stabilized cleavable complexes represent a block to fork progression (Fig. 1A and $8 \mathrm{~A})$.

Cells have evolved a variety of mechanisms for repairing DNA damage. The downregulation of replicon initiation rate provides more time for repairing damage before DNA replication and so should interact synergistically with DNA repair pathways to reduce the risk of S-phase-dependent mutations and chromatid aberrations $(18,29)$. The response pathway of inhibition of replicon initiation appears to share regulatory elements with a pathway which produces $G_{2}$ arrest. Both pathways are susceptible to inhibition by caffeine (i.e., caffeine prevents the down regulation of replicon initiation rate [29] and reduces the length of $G_{2}$ arrest [38]). Diploid AT fibroblasts also demonstrate radiation-resistant replicon initiation (32) and reduced $G_{2}$ delay following irradiation (43). Evidently, the pathways of downregulation of replicon initiation and $G_{2}$ delay normally provide more time for repair of potentially lethal (23) and potentially clastogenic $(8,28)$ cellular damage. It is notable in this regard that treatment of Chinese hamster ovary cells with etoposide or $\mathrm{X}$ irradiation has been shown to produce a rapid inhibition of $\mathrm{p} 34^{c d c 2}$ kinase activity, which was proposed as the mechanism of $G_{2}$ delay (24). Thus, it appears that the biochemical pathways which induce cell cycle delays after genomic damage also share components with the pathways which normally regulate cell growth and division (10).

\section{ACKNOWLEDGMENTS}

We are grateful to Jean-Michel Vos and Stephen Chaney for reading the manuscript and providing helpful comments.

This work was supported by Public Health Service grant CA42765 from the National Cancer Institute.

\section{REFERENCES}

1. Aurias, A., M. F. Croquette, J. P. Nuyts, C. Griscelli, and B. Dutrillaux. 1986. New data on clonal anomalies of chromosome 14 in ataxia telangiectasia: tct(14;14) and inv(14). Human Genet. 72:22-30.

2. Bender, M. A., H. G. Griggs, and P. L. Walker. 1973. Mechanisms of chromosomal aberration production. I. Aberration induction by ultraviolet light. Mutat. Res. 20:387-402.

3. Berrios, M., N. Osheroff, and P. A. Fisher. 1985. In situ localization of DNA topoisomerase II, a major polypeptide component of the Drosophila nuclear matrix fraction. Proc. Natl. Acad. Sci. USA 82:4142-4146.

4. Boyer, J. C., W. K. Kaufmann, B. P. Brylawski, and M. Cordeiro-Stone. 1990. Defective postreplication repair in xeroderma pigmentosum variant fibroblasts. Cancer Res. 50:25932598.

5. Brill, S. J., S. DiNardo, K. Voelkel-Meiman, and R. Sternglanz. 1987. Need for DNA topoisomerase activity as a swivel for DNA replication and for transcription of ribosomal RNA. Nature (London) 326:414-416.

6. Chen, G. L., L. Yang, B. D. Rowe, B. D. Halligan, K. M. Tewey, and L. F. Liu. 1984. Nonintercalative antitumor drugs interfere with the breakage-reunion reaction of mammalian DNA topoisomerase II. J. Biol. Chem. 259:13560-13566.
7. Dinardo, S., K. Voekel, and R. Sternglanz. 1984. DNA topoisomerase II mutant of Saccharomyces cerevisiae: topoisomerase II is required for segregation of daughter molecules at the termination of DNA replication. Proc. Natl. Acad. Sci. USA 81:2616-2620.

8. Ejima, Y., and M. S. Sasaki. 1986. Enhanced expression of $\mathrm{X}$-ray- and UV-induced chromosome aberrations by cytosine arabinoside in ataxia telangiectasia cells. Mutat. Res. 159:117123.

9. Garg, L. C., S. DiAngelo, and S. T. Jacob. 1987. Role of DNA topoisomerase $I$ in the transcription of supercoiled rRNA gene. Proc. Natl. Acad. Sci. USA 84:3185-3188.

10. Hartwell, L. H., and T. A. Weinert. 1989. Checkpoints: controls that ensure the order of cell cycle events. Science 246:629-634.

11. Henner, W. D., and M. E. Blazka. 1986. Hypersensitivity of cultured ataxia-telangiectasia cells to etoposide. J. Natl. Cancer Inst. 76:1007-1011.

12. Horwitz, S. B., C. Chang, and A. P. Grollman. 1971. Studies on camptothecin. I. Effects on nucleic acid and protein synthesis. Mol. Pharmacol. 7:632-644.

13. Hsiang, Y.-H., R. Hertzberg, S. Hecht, and L. F. Liu. 1985. Camptothecin induces protein-linked DNA breaks via mammalian DNA topoisomerase I. J. Biol. Chem. 260:14873-14878.

14. Hsiang, Y.-H., M. G. Lihou, and L. F. Liu. 1989. Arrest of replication forks by drug-stabilized topoisomerase I-DNA cleavable complexes as a mechanism of cell killing by camptothecin. Cancer Res. 49:5077-5082.

15. Hsiang, Y.-H., H.-Y. Wu, and L. F. Liu. 1988. Proliferationdependent regulation of DNA topoisomerase II in cultured human cells. Cancer Res. 48:3230-3235.

16. Kalwinsky, D. K., A. T. Look, J. Ducore, and A. Fridland. 1983. Effects of epipodophyllotoxin VP-16-213 on cell cycle traverse, DNA synthesis and DNA strand size in cultures of human leukemic lymphoblasts. Cancer Res. 43:1592-1597.

17. Kao-Shan, C. S., K. Micetich, L. A. Zwelling, and J. WhangPeng. 1984. Cytogenetic effects of amsacrine on human lymphocytes in vivo and in vitro. Cancer Treat. Rep. 68:989-997.

18. Kaufmann, W. K. 1989. Pathways of human cell postreplication repair. Carcinogenesis 10:1-11.

19. Kaufmann, W. K., and J. E. Cleaver. 1981. Mechanisms of inhibition of DNA replication by ultraviolet radiation in normal human and xeroderma pigmentosum fibroblasts. J. Mol. Biol. 149:171-187.

20. Kaufmann, W. K., J. C. Boyer, B. A. Smith, and M. CordeiroStone. 1985. DNA repair and replication in human fibroblasts treated with ( \pm )-7r,8t-dihydroxy-9t,10t-epoxy-7,8,9,10-tetrahydrobenzo[a]pyrene. Biochim. Biophys. Acta 824:146-151.

21. Kaufmann, W. K., and S. J. Wilson. 1990. DNA repair endonuclease activity during synchronous proliferation of diploid human fibroblasts. Mutat. Res. 236:107-117.

22. Kohn, K. W., R. A. G. Ewig, L. C. Erickson, and L. A. Zwelling. 1982. Measurement of strand breaks and cross-links by alkaline elution. p. 379-401. In E. C. Friedberg and P. C. Hanawalt (ed.), DNA repair: a laboratory manual of research techniques. Marcel Dekker, Inc., New York.

23. Little, J. B., and H. Nagasawa. 1985. Effect of confluent holding on potentially lethal damage repair, cell cycle progression, and chromosomal aberrations in human normal and ataxia-telangiectasia fibroblasts. Radiat. Res. 101:81-93.

24. Lock, R. B., and W. E. Ross. 1990. Inhibition of p34 $4^{\mathrm{cdc} 2}$ kinase activity by etoposide or irradiation as a mechanism of $G_{2}$ arrest in Chinese hamster ovary cells. Cancer Res. 50:3761-3766.

25. Mattern, M. R., S.-M. Mong, H. F. Bartus, C. K. Mirabelli, S. T. Crooke, and R. K. Johnson. 1987. Relationship between the intracellular effects of camptothecin and the inhibition of DNA topoisomerase $I$ in cultured L1210 cells. Cancer Res. 47:1793-1798.

26. Mohamed, R., S. P. Singh, S. Kumar, and M. F. Lavin. 1987. A defect in DNA topoisomerase II activity in ataxia telangiectasia cells. Biochem. Biophys. Res. Commun. 149:233-238.

27. Nelson, W. G., L. F. Liu, and D. G. Coffey. 1986. Newly replicated DNA is associated with DNA topoisomerase II in cultured rat prostatic adenocarcinoma cells. Nature (London) 
322:187-189.

28. Olivieri, G., and A. Micheli. 1983. Mitotic delay and repair in human lymphocytes. Mutat. Res. 122:65-72.

29. Painter, R. B. 1980. Effect of caffeine on DNA synthesis in irradiated and unirradiated mammalian cells. J. Mol. Biol. 143:289-301.

30. Painter, R. B. 1985. Inhibition and recovery of DNA synthesis in human cells after exposure to ultraviolet light. Mutat. Res. 145:63-69.

31. Painter, R. B., and B. R. Young. 1976. Formation of nascent DNA molecules during inhibition of replicon initiation in mammalian cells. Biochim. Biophys. Acta 418:146-153.

32. Painter, R. B., and B. R. Young. 1980. Radiosensitivity in ataxia-telangiectasia: a new explanation. Proc. Natl. Acad. Sci. USA 77:7315-7317.

33. Pommier, Y., M. R. Mattern, R. E. Schwartz, and L. A. Zwelling. 1984. Absence of swivelling at sites of intercalatorinduced protein-associated deoxyribonucleic acid strand-breaks in mammalian cell nucleoids. Biochemistry 23:2922-2927.

34. Rose, K. M. 1988. DNA topoisomerases as targets for chemotherapy. FASEB J. 2:2474-2478.

35. Russo, G., M. Isobe, L. Pegoraro, J. Finan, P. C. Nowell, and C. M. Croce. 1988. Molecular analysis of a $t(7 ; 14)(q 35 ; q 32)$ chromosome translocation in a $\mathrm{T}$ cell leukemia of a patient with ataxia telangiectasia. Cell 53:137-144.

36. Smith, P. J., C. O. Anderson, and J. V. Watson. 1986. Predominant role for DNA damage in etoposide-induced cytotoxicity and cell cycle perturbation in human SV40-transformed fibroblasts. Cancer Res. 46:5641-5645.
37. Snapka, R. M. 1986. Topoisomerase inhibitors can selectively interfere with different stages of simian virus 40 DNA replication. Mol. Cell. Biol. 6:4221-4227.

38. Tolmach, L. J., R. W. Jones, and P. M. Busse. 1977. The action of caffeine on X-irradiated HeLa cells. I. Delayed inhibition of DNA synthesis. Radiat. Res. 71:653-665.

39. van Maanen, J. M. S., J. Retel, J. deVries, and H. M. Pinedo. 1988. Mechanism of action of antitumor drug etoposide: a review. J. Natl. Cancer Inst. 80:1526-1533.

40. Wang, J. C. 1985. DNA topoisomerases. Annu. Rev. Biochem. 54:665-697.

41. Wang, J. C., P. R. Caron, and R. A. Kim. 1990. The role of DNA topoisomerases in recombination and genetic stability: a double-edged sword? Cell 62:403-406.

42. Yang, L., M. S. Wold, J. J. Li, T. J. Kelley, and L. F. Liu. 1987. Roles of DNA topoisomerases in simian virus 40 DNA replication in vitro. Proc. Natl. Acad. Sci. USA 84:950-954.

43. Zampetti-Bosseler, F., and D. Scott. 1981. Cell death, chromosome damage, and mitotic delay in normal human, ataxia telangiectasia, and retinoblastoma fibroblasts after X-irradiation. Int. J. Radiat. Biol. 39:547-558.

44. Zwelling, L. A., E. Estey, L. Silberman, S. Doyle, and W. Hittleman. 1987. Effect of cell proliferation and chromatin conformation on intercalator-induced, protein-associated DNA cleavage in human brain tumor cells and human fibroblasts. Cancer Res. 47:251-257.

45. Zwelling, L. A., and M. R. Mattern. 1982. DNA repair deficiencies do not affect intercalator-induced cytotoxicity or DNA scission in human cells. Mutat. Res. 104:295-304. 